Trakya Üniversitesi

Eğitim Fakültesi Dergisi

XV. Uluslararası Katılımlı Sınıf Öğretmenliğ

Eğitimi Sempozyumu (11-14 Mayıs 2016)

USOS 2016 Özel Sayısı, 68-79

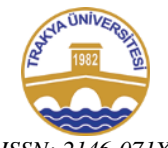

ISSN: 2146-071X
Trakya University

Journal of Education Faculty

XV. International Primary Teacher Education

Symposium (11-14 May 2016)

IPTES 2016 Special Issue, 68-79

Doi: 10.24315/trkefd.364039

\title{
Öğrenci Katılım Ölçeğinin Türkçeye Uyarlanması: Geçerlik ve Güvenirlik Çalışmasıs ${ }^{1}$
}

\section{The Adaptation of Student Engagement Scale to Turkish: The Validity and Reliability Study}

\author{
Gökhan YILDIRIM ${ }^{2}$,Yavuz SÖKMEN ${ }^{3}$,Yasemin TAŞ ${ }^{4}$, Mücahit \\ DİLEKMEN $^{5}$
}

Öz: Bu çalışmada, Mazer (2012) tarafından geliştirilmiş olan Student Engagement Scale (Öğrenci Katılım Ölçeği, ÖKÖ)'i Türkçeye uyarlamak, geçerlik ve güvenirlik analizlerini yapmak amaçlanmıştır. Üniversite öğrencilerinin katılımını ölçmek için geliştirilen ÖKÖ, 13 madde ve 4 boyuttan (sınıf içi sessiz davranışlar, sınıf içi sözlü davranışlar, ders içeriği hakkında düşünme ve sınıf dışı davranışlar) oluşmaktadır. İki ayrı çalışma yapılmıştır. Birinci çalışmada İngiliz Dili Eğitimi Programı öğrencilerine $(\mathrm{n}=25)$ ölçeğin İngilizce ve Türkçe formu 2 hafta ara ile verilmiştir. Katılımcıların iki forma verdikleri yanıtlar arasında yüksek düzeyde ve pozitif yönde ilişki bulunmuştur $(\mathrm{r}=.80)$. İkinci çalışmaya ise matematik ve sınıf öğretmenliği bölümlerinde okuyan 146 öğretmen adayı katılmıştır. Doğrulayıcı faktör analizi sonuçları, önerilen modelin, veri seti ile iyi uyum sağladığını göstermiştir. Ölçeğin alt boyutlarına ait Cronbach Alpha güvenirlik katsayıları .70 ile .91 arasında değişmiştir. Analiz sonuçları, ÖKÜ'nün geçerliliği ve güvenirliği hakkında delil sağlamıştır.

Anahtar sözcükler: Öğrenci katılımı, ölçek uyarlama, üniversite ögrencileri

\begin{abstract}
This study aimed to adapt Student Engagement Scale (SES, Mazer, 2012) to Turkish and conduct validity and reliability analyses. SES, developed to measure university students' engagement, consists of 13 items and 4 dimensions (silent in class behaviors, oral in class behaviors, thinking about course content, and out of class behavior). Two separate studies were conducted. In the first study, students in English language teaching program $(n=25)$ completed English and Turkish versions of the scale in two weeks
\end{abstract}

\footnotetext{
1 Bu çalışma 11-14 Mayıs 2016 tarihinde Muğla Sitkı Koçman Üniversitesi tarafindan düzenlenen XV. Uluslararası Sınıf Öğretmenliği Eğitimi Sempozyumu'nda sözlü bildiri olarak sunulmuştur.

2 Arş. Gör., Atatürk Üniversitesi, gokhanyildirim2751@gmail.com

3 Arş. Gör., Atatürk Üniversitesi, y_sokmen24@hotmail.com

4 Yrd. Doç.Dr., Atatürk Üniversitesi, tasyase@gmail.com

5 Doç. Dr., Atatürk Üniversitesi, dilekmen@atauni.edu.tr
} 
interval. There was a high and positive correlation between responses given to two versions of the scale $(r=.80)$. In the second study, 146 students in mathematics and primary teacher education programs participated. Confirmatory factor analysis showed that the proposed model fit well to the data. Cronbach Alpha coefficients for subscales ranged from .70 to .91. Analysis results provided evidence about the validity and reliability of the Turkish version of the scale.

Keywords: Student engagement, scale adaptation, undergraduate students

\section{GíRiș}

Son zamanlarda birçok araştırmaya (ör. Baron ve Corbin, 2012; Kahu, 2013; Leach, 2016; Lee, 2014; Olwage ve Mostert, 2014; Yin ve Wang, 2015) konu olan öğrenci katılımı (student engagement), araştırmacılar tarafindan farklı şekillerde ele alınmıştır. Kuh'a (2009) göre katılım oldukça basit ve kolay anlaşılabilen bir terimdir. Kuh (2009) katılımı, bir çalışmaya daha fazla öğrencinin dahil olması, öğrencilerin bildikleri hakkında daha fazlasına ulaşması, daha fazla öğrencinin uygulama sürecine katılması, öğrencilerin çalışmaları ve problem çözme becerilerine ilişkin öğretmenlerden geri bildirim alması ve böylelikle onların öğrenmelerinden anlamlandırdıklarını derinleştirmesi, kompleks durumları daha iyi yönetebilmesi, belirsiz durumlarla daha iyi başa çıkabilmesi ve gerek farklı geçmişe gerekse farklı görüşlere sahip bireylerle çalışılabilmesi olarak tanımlamaktadır. Fredricks, Blumenfeld ve Paris (2004) ise katılımı; davranışsal (behavioral), duyuşsal (emotional) ve bilişsel (cognitive) boyutları kapsayan çok boyutlu bir kavram olarak ele almaktadır.

Davranışsal katılım genellikle öğrencilerin okul içi ve okul dışı etkinliklere katılımlarını kapsayan etkinliklerdeki tutum, çaba ve süreklilik olarak ele alınmaktadır (Fredricks vd., 2004; Skinner, Kindermann ve Furrer, 2008; Lee, 2014). Davranışsal katılım; sınıf kurallarına uyma, sınıftaki normları devam ettirme ve devamsızlıktan kaçınma gibi davranışları içeren olumlu davranışlar geliştirme; sınıf içi tartışmalara katkı sağlayarak, sorular sorarak, olumlu davranışlar göstererek ve öğrenmeye ilişkin bir çaba ortaya koyarak öğretim etkinliklerine akademik katılım sağlama; okul yönetimi ve okula ilişkin kararlar alma gibi davranışlarla okul faaliyetlerine katılma olmak üzere 3 farklı boyutta ele alınmaktadır (Fredricks vd., 2004). Bir başka araştırmada ise davranışsal katılım, süreklilik, derse odaklanma, derse tüm dikkatini verme ve öğretim etkinliklerinde bir gayret gösterme gibi unsurları kapsayan görev davranısları, akademik davranışlar ve derse katılım alt boyutları ile ele alınmıştır (Skinner, Kindermann ve Furrer, 2008). Genel olarak davranışsal katılım, öğrencilerin dersteki etkinliklere aktif bir biçimde katılması, sınıf ve okul kurallarına uyması ve dersteki görevlerini isteyerek ve içtenlikle yapması şeklinde ele alınabilir (Fredricks vd., 2004; Harris, 2008; Kahu, 2013; Reeve ve Lee, 2014; Skinner, Kindermann ve Furrer, 2008).

Duyuşsal katılım öğrencilerin derse, okula, öğretmenlerine ve sınıf arkadaşlarına karşı sıkılma, kaygı ve öfke hislerinden arınmış olarak derslere istekli bir şekilde çalışmalarını, katılmalarını ve çevreleriyle bir takım ilişkiler 
kurmalarını sağlayan tutum ve davranışları kapsamaktadır (Parsons ve Taylor, 2011; Reeve ve Tseng, 2011). Fredricks vd. (2004) duyuşsal katılımın sadece olumlu tutum ve davranışları değil aynı zamanda kaygı, endişe ve mutsuzluk gibi olumsuz tutum ve davranışları da içerdiğini belirtmişlerdir. Meyer ve Turner (2006) öğrenme motivasyonu için gerekli olan olumlu öğretmen-öğrenci ilişkisi ve etkileşimine katkı sağlayan duyuşsal katılımın öğrenmedeki gerekliliğine dikkat çekmiştir. Duyuşsal katılımın sağlanabilmesi ve öğrencilerde bir merak duygusu uyandırılabilmesi için gerek öğretmende gerekse yazılı materyallerde eğlendirici ipuçları vardır. Bu ipuçlarının nasıl kullanıldığ öğrencilerin öğrenme isteklerini, enerjilerini, meraklarını ve derse karşı sergiledikleri tutum ve davranışlarını etkilemektedir (Mazer, 2012).

Bilişsel katılım öz düzenleme, gelişmiş öğrenme stratejileri uygulama ve öğrenme sürecine bireysel olarak katılma olarak düşünülmektedir (Fredricks vd., 2004; Parsons ve Taylor, 2011; Reeve ve Tseng, 2011; Steele, 2015). Öğrenci katılımında öz yeterlilik, motivasyon, öğretmenlerin isteklerini, dikkatlerini ve beklentilerini algılama gibi öğrencilerin okulla, öğretmenleriyle, diğer öğrencilerle ve kendileriyle olan algıları ve inançları bilişsel katılım ile ilgili boyutları kapsamaktadır (Jimerson, Campos ve Greif, 2003). Fredricks ve arkadaşları (2004) literatürde bilişsel katılımın iki farklı boyutu üzerinde durulduğunu ifade etmişlerdir. Bunlardan birincisi ögrencilerin ögrenme sürecine psikolojik katılımlarıdır. İkincisi ise ögrenme sürecinde gelişmiş ögrenme stratejilerinin kullanılmasıdır. Fakat Fredricks ve arkadaşları (2004) bu iki boyutun tek başına bir anlam ifade etmeyeceğinin altını çizerek bilişsel katılımın hem psikolojik katılımla hem de öğrenme stratejilerini kullanma ile ilişkili olduğunu belirtmişlerdir.

Görüldüğü üzere, birçok araştırmacı öğrenci katılımı kavramına farklı açılardan bakmış ve farklı tanımlar geliştirmişlerdir. Öğrenci katılımı, öğrenci başarısını ve deneyimini geliştiren (Baron ve Corbin, 2012) öğrencilerin akademik ilerlemelerini ve başarılarını tahmin eden (Reeve ve Tseng, 2011) öğrencilerin öğrenme sürecine psikolojik katılımlarını da kapsayan (Turner, Christensen, Kackar-Cam, Trucano ve Fulmer, 2014) ve çoğunlukla olumlu davranışlarla ve akademik başarıyla ilişkilendirilen (Willms, Friesen ve Milton, 2009) çok yönlü bir kavram (Lee, 2014) olarak tanımlanmaktadır. Günümüzde ise öğrenci katılımı ağırlıklı olarak genellikle derste öğrencilerin ortaya koyduğu performansın niteliği ve yaratıcı öğretim etkinliklerine katılım gibi süreçleri temsil etmek için kullanılmaktadır (Kuh, 2009).

Yakın zamanda Mazer (2012) ise üniversite öğrencilerinin katılım düzeyini ölçmek için yeni bir ölçek geliştirmiştir: Student Engagement Scale (SES; Öğrenci Katılım Ölçeği, ÖKÖ). Ölçek 7'li likert tipte (1= hiç bir zaman, 7= her zaman) olup toplam 13 madde ve 4 boyuttan oluşmaktadır. Birinci boyut sınıf içi sessiz davranışlar için örnek madde "Ders boyunca dersi veren öğretim elemanını dikkatlice dinlerim", ikinci boyut sınıf içi sözlü davranışlar için örnek madde "Fikirlerimi dile getirerek sınıf içi tartışmalara katılırım", üçüncü boyut ders içeriği hakkında düşünme için örnek madde "Ders konuları ile hayatım arasında bağlantı kurarım" ve dördüncü boyut sınıf dışı davranışlar için örnek madde "Ders dışında notlarımı gözden geçiririm” şeklinde verilebilir. Ölçeğin alt boyutlarına ait 
Cronbach Alpha güvenirlik katsayıları sınıf içi sessiz davranışlar için .77; sınıf içi sözlü davranışlar için .93; ders içeriği hakkında düşünme için .91 ve sınıf diş1 davranışlar için .70'dir. Bu ölçeği kullanarak yapılan bazı çalışmalar vardır. Örneğin, öğrenci katılımı ile öğretmen yanlış davranışı arasında negatif yönde (Broeckelman-Post, Tacconelli, Guzmán, Rios, Calero, ve Latif, 2016) öğrenci katılımı ile öğretmenin kavramsal becerileri arasında pozitif yönde bir ilişki bulunmuştur (Noland ve Richards, 2015).

İlgili alan yazında görüldüğü gibi öğrenci katılımı akademik başarı gibi birçok öğrenci çıktısıyla ilişkili olan önemli bir kavramdır. Bu çalışmada, Mazer (2012) tarafından üniversite öğrencilerinin derslere katılım düzeylerini ölçmek amacıyla geliştirilmiş olan Öğrenci Katılım Ölçeği (ÖKÖ)'nin Türkçeye uyarlanması ve Türkçe formunun geçerlik ve güvenirlik çalışmalarını yapmak amaçlanmıştır.

\section{YÖNTEM}

\section{Katılımcilar}

Mazer (2012) tarafından geliştirilen ÖKÖ’nin Türkçeye uyarlanması amacıyla yapılan bu çalışmanın evrenini 2015-2016 öğretim yılında Atatürk Üniversitesi Kazım Karabekir Eğitim Fakültesi'nde öğrenim görmekte olan öğretmen adayları oluşturmaktadır. Katılımcılar uygun örnekleme (convenience sampling) ile oluşturulmuştur. Çalışma 2 ayrı örneklem üzerinde yürütülmüştür. İlk çalışma 19 (\%76)'u kadın, 6 (\%24)'sı erkek olmak üzere toplam 25 öğretmen adayının katılımı ile gerçekleştirilmiştir. Bu öğrenciler, İngiliz Dili ve Eğitimi anabilim dalı 3. Sınıfta öğrenim görmektedir. İkinci çalışma ise 146 öğretmen adayı üzerinde yürütülmüştür. Katılımcıların 88 (\% 60.3)'i sınıf öğretmenliği, 58 (39.7)'i ilköğretim matematik öğretmenliğinde öğrenim görmekte olup 116 (\%79.5)'sı kadın, 30 (\%20.5)'u erkektir. Öğretmen adaylarının 56 (\%38.4)'s1 ikinci sınıfta, 85 (\%58.2)'i üçüncü sınıfta ve 5 (\%3.4)'i dördüncü sınıftadır. Katılımcıların yaş aralığı 18 ile 32 arasında değişmektedir $(\bar{X}=20.58$, ss $=1.62)$. 9 öğretmen adayı ise yaşını belirtmemiştir.

\section{Verilerin Analizi}

ÖKÖ’nin dil geçerliği için İngilizce ve Türkçe formalarına verilen yanıtlar arasındaki ilişki Pearson korelasyon katsayısı ile ölçülmüştür. Ölçeğin Türk kültüründe yapı geçerliğini incelemek için doğrulayıcı faktör analizi (DFA) kullanılmıştır. DFA, açımlayıcı faktör analizi (AFA) ile ortaya konulan bir yapının bazı parametreler açısından doğruluğunun test edilmesi (Jöreskog ve Sörbom, 1993) amacıyla ileri düzey araştırmalarda kullanılan son derece gelişmiş bir testtir (Tabachnick ve Fidell, 2001). DFA'da model içinde kullanılacak her gizil değişkene ait ilgili değişkenlerin gerçekten bağlı oldukları gizil değişkeni açıklayıp açıklamadığı ölçülür. Yani ortaya konulan modelin eldeki mevcut verilerle teorik olarak örtüşüp örtüşmediği incelenir (Meydan ve Şeşen, 2011; Schumacker ve Lomax, 2004). Verilerin analizinde LISREL 8.1 paket programı kullanılarak DFA yapılmış ve çoklu uyum indeksleri ( $\chi^{2} / \mathrm{df}$, RMSEA, S-RMR, NNFI, CFI) incelenerek model uyumu test edilmişstir. Bu indekslerden $\chi^{2} / \mathrm{df}$ 'nin 2'nin altında olması mükemmel uyuma işaret etmektedir (Seçer, 2014; Tabachnick 
ve Fidell, 2001). RMSEA'nin 0.07'nin altında olması (Steiger, 2007), S-RMR'nin ise 0.08'in altında olması (Hu \& Bentler, 1999) iyi uyum olduğu şeklinde yorumlanırken; NNFI ve CFI'nin 0.90'in üzerinde olması iyi uyum olduğunu göstermektedir (Kelloway, 1998; Tabachnick ve Fidell, 2001). Ölçeğin alt boyutlarına ait güvenirlik katsayısı Cronbach Alpha ile hesaplanmıştır.

\section{BULGULAR}

\section{Dil Geçerliği ve Ölçeğin Türkçe Formunun Oluşturulması}

Birinci çalışmada ölçeğin dil geçerliğini belirlemek üzere öncelikle İngiliz Dili ve Eğitimi programı 3. sınıfta öğrenim görmekte olan 25 öğretmen adayına ölçeğin orijinal formu uygulanmıştır. Dil geçerliği için kullanılacak örneklem öğrencilerin akademik olarak belirli düzeye ulaşmış olmaları kanaati ve derslere devam durumları göz önünde bulundurularak özellikle 3. sınıflardan seçilmiştir. Ölçeğin Türkçe uyarlama formunu oluşturmak için alanında uzman iki araştırma görevlisi, iki öğretim üyesi, bir İngilizce öğretmeni ve bir de Türk Dili ve Edebiyatı uzmanı olmak üzere toplamda altı kişi komisyona katılmıştır. İlk olarak ölçeğin uygulanacağı yaş grubu dikkate alınarak maddeler üç yazar ve üç İngiliz Dili ve Eğitimi anabilim dalında görev yapan öğretim üyesi tarafından Türkçeye çevrilmiştir. Daha sonra, oluşturulan komisyon bir araya gelerek maddeler üzerinde tartışmıştır. Son olarak, Türkçeye çevrilen ölçek iki Türk Dili ve Edebiyatı uzmanına sunularak maddelerin dil bilgisi ve anlaşılırlığı açısından değerlendirilmesi istenmiştir. Alınan dönütler doğrultusunda gerekli düzeltmeler yapılarak ölçeğe son hali verilmiştir. Ölçeğin orijinal formunun İngilizce ögretmenliği anabilim dalındaki öğretmen adaylarına uygulanmasından iki hafta sonra ölçeğin Türkçe formu aynı örneklem grubuna uygulanmıştır. İki uygulamadan elde edilen veriler arasındaki ilişki Pearson korelasyon katsayısı $(r)$ ile hesaplanmıştır. Yapılan korelasyon analizi sonucunda iki ölçekten elde edilen puanlar arasında yüksek düzeyde ve pozitif yönde anlamlı bir ilişki olduğu sonucuna ulaşılmıştır $(r=.80, p<.05)$. Bu sonuç, ölçeğin Türkçe formunun dil geçerliği konusunda kanıt sağlamıştır.

\section{Doğrulayıcı Faktör Analizi (DFA)}

Çalışmanın ikinci aşamasında ise yeni bir örneklem $(n=146)$ üzerinden çalışmada uyarlaması yapılan ölçeğin faktör yapısının veri seti ile uyumlu olup olmadığını araştırmak için LISREL 8.1 programı kullanılarak Doğrulayıcı Faktör Analizi (DFA) yapılmıştır. Analiz sonuçları incelendiğinde, modifikasyon değerleri dördüncü maddenin (Derslere katılırım) "sınıf içi sessiz davranışlar" boyutu yerine "sınıf içi sözlü davranışlar" boyutunda yer alması gerektiğini göstermiş̧tir. Türkiye'deki durum göz önüne alındığında bunun uygun olduğu düşünülmektedir. Çünkü Türkiye'de "derslere katılırım” ifadesi öğrenciler tarafından sözlü katılım olarak anlaşılmaktadır. Dördüncü maddenin sınıf içi sözlü davranışlar boyutuna dahil edilmesine karar verilmiş ve tekrar DFA yapılmıştır. Uyum indekslerine göre önerilen 4 faktörlü yapının veri seti ile iyi uyum sağladığ 1 belirlenmiştir $\left(\chi^{2} / \mathrm{df}=1.70, \mathrm{RMSEA}=0.070, \mathrm{~S}-\mathrm{RMR}=0.068, \mathrm{NNFI}=0.947, \mathrm{CFI}=\right.$ 0.960). Her bir maddenin faktör yükünün (LAMBDA-X değerleri) 0.60 ve üzerinde olduğu gözükmektedir (Bkz. Şekil 1). 


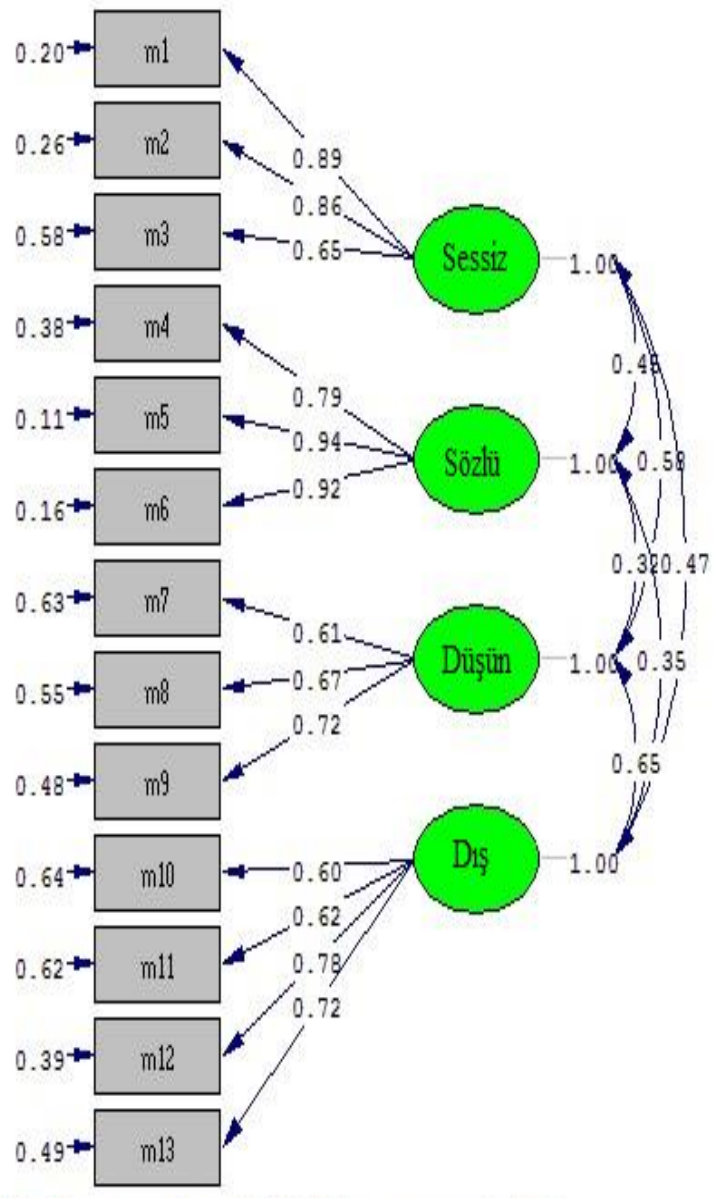

Chi-Square $=100.61, d f=59, P-$ value $=0.00060$, RMSEA $=0.070$

Şekil 1. Faktör yükleri

ÖKÜ'nün son haline ait ortalama, standart sapma ve madde-toplam korelasyon değerleri Tablo 1'de verilmiştir. Madde-toplam madde korelasyonlar1 da 0.44 ve üzerinde çıkmıştır. Ölçeğin alt boyutlarına ait güvenirlik katsayıları Cronbach Alpha ile hesaplanmıştır. Cronbach Alpha güvenirlik katsayıları sınıf içi sessiz davranışlar için (3 madde) .81, sınıf içi sözlü davranışlar için (3 madde) .91, ders içeriği hakkında düşünme için (3 madde) .70 ve sınıf dışı davranışlar için (4 madde) .77 olarak hesaplanmıştır.

Tablo 1. ÖKÖ’ nün son haline ait ortalama, standart sapma ve madde-toplam korelasyon değerleri 


\begin{tabular}{|c|c|c|c|c|}
\hline & Alt Boyutlar ve Maddeler & Ortalama & $\begin{array}{l}\text { Standart } \\
\text { Sapma }\end{array}$ & $\begin{array}{c}\text { Madde- } \\
\text { toplam } \\
\text { korelasyon }\end{array}$ \\
\hline & Sınıf İçi Sessiz Davranışlar & & & \\
\hline 1 & $\begin{array}{l}\text { Ders boyunca dersi veren öğretim } \\
\text { elemanını dikkatlice dinlerim. }\end{array}$ & 4.80 & 1.41 & 0.58 \\
\hline 2 & $\begin{array}{l}\text { Ders boyunca tüm dikkatimi öğretim } \\
\text { elemanına veririm }\end{array}$ & 4.49 & 1.32 & 0.61 \\
\hline 3 & $\begin{array}{l}\text { Dersle ilgili tartışmalarda } \\
\text { arkadaşlarımın derse katılımlarını } \\
\text { dikkatlice dinlerim . } \\
\text { Sınıf İçi Sözlü Davranışlar }\end{array}$ & 4.91 & 1.41 & 0.61 \\
\hline 4 & Derslere katılırım. & 4.37 & 1.57 & 0.61 \\
\hline 5 & $\begin{array}{l}\text { Fikirlerimi dile getirerek sınıf içi } \\
\text { tartışmalara katılırım. }\end{array}$ & 4.10 & 1.71 & 0.54 \\
\hline 6 & $\begin{array}{l}\text { Dersle ilgili tartışmalara sözlü olarak } \\
\text { katılırım. } \\
\text { Ders İçeriği Hakkında Düşünme }\end{array}$ & 4.05 & 1.64 & 0.57 \\
\hline 7 & $\begin{array}{l}\text { Günlük yaşamımda ders } \\
\text { materyallerinden nasıl faydalanacağımı } \\
\text { düşünürüm. }\end{array}$ & 4.79 & 1.41 & 0.49 \\
\hline 8 & $\begin{array}{l}\text { Ders konuları ile hayatım arasında } \\
\text { bağlantı kurarım. }\end{array}$ & 4.92 & 1.48 & 0.49 \\
\hline 9 & $\begin{array}{l}\text { Ders konularının gelecekteki } \\
\text { kariyerimde nasıl fayda sağlayacağını } \\
\text { düşünürüm. } \\
\text { Sınıf Dışı Davranışlar }\end{array}$ & 5.50 & 1.33 & 0.49 \\
\hline 10 & $\begin{array}{l}\text { Ders dışında notlarımı gözden } \\
\text { geçiririm. }\end{array}$ & 4.71 & 1.49 & 0.47 \\
\hline 11 & Sınavlarıma çalışırım. & 5.49 & 1.48 & 0.44 \\
\hline 12 & $\begin{array}{l}\text { Ders dışında arkadaşlarımla ders } \\
\text { konularını tartışırım. }\end{array}$ & 4.53 & 1.55 & 0.59 \\
\hline 13 & $\begin{array}{l}\text { Dersle ilgili ek materyallere kendi } \\
\text { kendime çalışırım. }\end{array}$ & 4.27 & 1.67 & 0.50 \\
\hline
\end{tabular}

\section{TARTIŞMA ve SONUÇ}

Bu çalışmada, Mazer (2012) tarafindan üniversite öğrencilerinin derslere katılım düzeylerini ölçmek amacıyla geliştirilmiş olan Student Engagement Scale (SES; Öğrenci Katılım Ölçeği, ÖKÖ)'in Türkçeye uyarlaması ve Türkçe formunun geçerlik ve güvenirlik çalışmalarını yapmak amaçlanmıştır. Ölçeğin dilsel geçerliliği için İngilizce ve Türkçe versiyonlarından elde edilen puanlar arasındaki ilişki incelenmiş ve yüksek pozitif $(r=.80)$ bir ilişki olduğu belirlenmiştir. İkinci çalışmada ise; ölçeğin yapı geçerliliğini test etmek için DFA yapılmıştır. Ölçeğin Türkçe versiyonunda, orijinali gibi 4 alt boyuttan (sınıf içi sessiz davranışlar, sınıf içi sözlü davranışlar, ders içeriği hakkında düşünme ve sınıf dışı davranışlar) oluştuğu sonucuna varılmışıtır. Ancak bir maddenin yer 
aldığg boyut değiştirilmiştir. "Derslere katılırım” maddesi, sınıf içi sessiz davranışlar boyutu yerine sınıf içi sözlü davranışlar boyutuna alınmıştır. Bu durumun kültürler arası farklılıktan kaynaklandığı düşünülmektedir. Çünkü Türkiye'de derslere katılma ifadesi öğrenciler tarafindan sözlü katılım olarak anlaşılmaktadır. DFA sonucunda uyum indeksleri $\left(\chi^{2} / \mathrm{df}=1.70, \mathrm{RMSEA}=0.070\right.$, $\mathrm{SRMR}=0.068$, NNFI=0.947, CFI=0.960) iyi uyum olduğunu göstermiştir. Alt boyutlara ait Cronbach Alpha değerleri ise .70 ile .91 arasında değişmiştir. Bu sonuçlar 1şı̆̆ında, ölçeğin öğretmen adaylarının katılımını belirlemede geçerli ve güvenilir bir ölçme aracı olduğu söylenebilir.

Araştırma örnekleminin bir üniversitenin eğitim fakültesinde öğrenim gören öğretmen adayları oluşturmaktadır. Bu araştırmanın bir sınırlılığı olarak görülebilir. Ölçeğin farklı örneklemlerle test edilmesi, ölçekten elde edilen sonuçların genellenebilirliği açısından önemli gözükmektedir. Ayrıca, ölçüt bağıntılı geçerliliğini test etmek için farklı ölçeklerle ilişkisine bakılabilir. Ek olarak, ölçekten elde edilen puanların zaman içerisinde kararlığına bakmak için test tekrar test güvenirliği incelenebilir. 


\section{KAYNAKLAR}

Baron, P. \& Corbin, L. (2012). Student engagement: rhetoric and reality. Higher Education Research ve Development, 31(6), 759-772.

Broeckelman-Post, M. A., Tacconelli, A., Guzmán, J., Rios, M., Calero, B. \& Latif, F. (2016). Teacher Misbehavior and its Effects on Student Interest and Engagement. Communication Education, 65(2), 204-212.

Fredricks, J. A., Blumenfeld, P. C. \&Paris, A. H. (2004). School engagement: Potential of the concept, state of the evidence. Review of Educational Research, 74(1), 59-109.

Harris, L. R. (2008). A phenomenographic investigation of teacher conceptions of student engagement in learning. The Australian Educational Researcher, 35(1), 57-79.

Hu, L. T. \& Bentler, P. M. (1999). Cutoff criteria for fit indexes in covariance structure analysis: Conventional criteria versus new alternatives. Structural equation modeling: a multidisciplinary journal, 6(1), 1-55.

Jimerson, S. R., Campos, E. \& Greif, J. L. (2003). Toward an understanding of definitions and measures of school engagement and related terms. The California School Psychologist, 8(1), 7-27.

Jöreskog, K. G. \& Sörbom, D. (1993). LISREL 8: Structural equation modeling with the Simplis command language. Lincolnwood: Scientific Software International, Inc.

Kahu, E. R. (2013). Framing student engagement in higher education. Studies in Higher Education, 38(5), 758-773.

Kelloway, E. K. (1998). Using LISREL for Structural Equation Modelin: A reseracher's guide. Thousand Oaks, CA: Sage.

Kuh, G. (2009). The national survey of student engagement: Conceptual and empirical foundations. New Directions for Institutional Research, 141, $5-20$.

Leach, L. (2016). Enhancing student engagement in one institution. Journal of Further and Higher Education, 40(1), 23-47.

Lee, J. S. (2014). The Relationship Between Student Engagement and Academic Performance: Is It a Myth or Reality?. The Journal of Educational Research, 107(3), 177-185.

Mazer, J. P. (2012). Development and validation of the student interest and engagement scales. Communication Methods and Measures, 6(2), 99-125, DOI: $\quad 10.1080 / 19312458.2012 .679244$.

Meydan, C. H. \& Şeşen, H. (2011). Yapısal eşitlik modellemesi AMOS uygulamaları. Ankara: Detay Yayıncılık.

Meyer, D. K. \& Turner, J. C. (2006). Re-conceptualizing emotion and motivation to learn in classroom contexts. Educational Psychology Review, 18(4), 377-390. 
Noland, A. \& Richards, K. (2015). Servant Teaching: An exploration of teacher servant leadership on student outcomes. Journal of the Scholarship of Teaching and Learning, 15(6), 16-38.

Olwage, D. \&Mostert, K. (2014). Predictors of student burnout and engagement among university students. Journal of Psychology in Africa, 24(4), 342350 .

Parsons, J. \& Taylor, L. (2011). Student Engagement: What Do We Know and what Should We Do? University of Alberta.

Reeve, J. \& Tseng, C. M. (2011). Agency as a fourth aspect of students' engagement during learning activities. Contemporary Educational Psychology, 36(4), 257-267.

Reeve, J. \& Lee, W. (2014). Students' classroom engagement produces longitudinal changes in classroom motivation. Journal of Educational Psychology, 106(2), 527-540.

Schumacker, R. E. \& Lomax, R. G. (2004). A beginner's guide to structural equation modeling. NJ: Lawrence Erlbaum Associates. .

Seçer, İ. (2014). Ergenlerde obsesif kompulsif bozukluk ile anksiyete duyarlılığı arasındaki ilişkinin yapısal eşitlik modeli ile incelenmesi. Eğitim ve Bilim, 39(176), 369-382.

Skinner, E. A., Kindermann, T. A. \&Furrer, C. J. (2008). A motivational perspective on engagement and disaffection: Conceptualization and assessment of children's behavioral and emotional participation in academic activities in the classroom. Educational and Psychological Measurement. 69(3), 493-525. DOI:10.1177/0013164408323233.

Steele, G. A. (2015). New postgraduate student experience and engagement in human communication studies. Journal of Further and Higher Education, 39(4), 498-533.

Steiger, J.H. (2007). Understanding the limitations of global fit assessment in structual equation modeling .Personality and Individual Differences, 42(5), 893-898.

Tabachnick, B. G., Fidell, L. S. (2001). Using multivariate statistics. (Fourth Edition). MA: Allyn \& Bacon, Inc.

Turner, J. C., Christensen, A., Kackar-Cam, H. Z., Trucano, M. \&Fulmer, S. M. (2014). Enhancing Students' Engagement Report of a 3-Year Intervention With Middle School Teachers. American Educational Research Journal, 51(6), 1195-1226.

Willms, J. D., Friesen, S. \& Milton, P. (2009). What did you do in school today? Transforming classrooms through social, academic and intellectual engagement. (First National Report) Toronto: Canadian Education Association.

Yin, H. \& Wang, W. (2015). Undergraduate students' motivation and engagement in China: an exploratory study. Assessment ve Evaluation in Higher Education, 41(4), 601-621, DOI: 10.1080/02602938.2015.1037240. 


\section{EXTENDED ABSTRACT}

\section{Introduction}

Student engagement refers to the quality of the student performance in the class and participation in class activities (Kuh, 2009). Student engagement is a multidimensional construct (Lee, 2014) and it is positively related to academic achievement (Baron \& Corbin, 2012; Reeve \& Tseng, 2011; Willms, Friesen \& Milton, 2009). Recently, Mazer (2012) has developed Student Engagement Scale (SES) to measure university students' engagement. The SES includes 13 items and 4 subscales which are (1) silent in class behaviors, (2) oral in class behaviors, (3) thinking about course content, and (4) out of class behaviors. Silent in class behavior refers to students' following the lectures and class discussions carefully (Example item: "Listened attentively to the instructor during class"). Oral in class behavior is about students' willingness to participate in class activities (Example item: "Participated during class discussions by sharing your thoughts/opinions"). Thinking about course content refers to students' linking course content to their daily life and thinking deeply about the course content (Example item: "Thought about how the course material related to your life"). Lastly, out of class behaviors is about students' out of class studies and preparation for their exams (Example item: "Reviewed your notes outside of class") The items of the scale are responded on a 7 point Likert format from never (1) to always (7). The aim of the present study was to translate and adapt SES (Mazer, 2012) into Turkish and conduct validity and reliability analyses.

\section{Method}

Firstly, items of the SES were translated into Turkish by six experts in the field. Then, Turkish version of the scale was examined by two experts and necessary revisions were made. Then, linguistic validity, factor structure, and reliability of the scale were investigated. A total of 171 pre-service teachers at Atatürk University Kazım Karabekir Faculty of Education participated in this study. The data were collected during the 2015-2016 academic year. The samples of the study were selected through convenience sampling. Two samples were selected. The first sample consisted of 25 pre-service teachers (76\% females and $24 \%$ males) from the Department of English Language Teaching.. They were third grade students. The original form and Turkish form of the scale were administrated to the sample within two weeks interval. The second sample consisted of 146 preservice teachers from different departments $(60.3 \%$ from department of primary teacher education, and $39.7 \%$ from department of mathematics teaching). Of these participants, $56(38.4 \%)$ were at the second grade, $85(58.2 \%)$ were at the third grade, $5(3.4 \%)$ were at the fourth grade in their programs. The age of participated range from 18 to 32 and the mean age was $20.58(S D=1.62)$ years.

\section{Findings and conclusion}

The data obtained from the first sample were subjected to the correlation analysis. The Pearson correlation coefficient between the English and Turkish versions of the scale was high $(r=.80, p<.05)$ indicating consistency of the scores obtained from the two versions of the scale. This finding supports linguistic validity of the scale. The data obtained from the second sample were subjected to factor analysis. 
In order to test the proposed four-factor structure of the scale, confirmatory factor analysis (CFA) was conducted by using LISREL 8.1 program. Several fit indices were examined to evaluate goodness of model fit. Among these indices, $\chi^{2} / \mathrm{df}$ is recommended to be below 2 (Seçer, 2014; Tabachnick \& Fidell, 2001), RMSEA is suggested to be below 0.07 (Steiger, 2007), and S-RMR is recommended to be below 0.08 (Hu \& Bentler, 1999) for good model fit. On the other hand, NNFI and CFI above 0.90 show good model fit (Kelloway, 1998; Tabachnick \& Fidell, 2001). When analysis results were examined, modification indices suggested that item 4 ("Attended class") should belong to the factor of "oral in class behaviors" rather than the factor of "silent in class behaviors". This was meaningful in the context of Turkey because students can interpret attending to the class as oral participation. Therefore, the item was placed under the factor of "oral in class behaviors" and CFA was conducted again. Analysis results indicated good model fit $\left(\chi^{2} / \mathrm{df}=1.70, \mathrm{RMSEA}=0.070, \mathrm{~S}-\mathrm{RMR}=0.068, \mathrm{NNFI}=0.947, \mathrm{CFI}=0.960\right)$. Considering these indices it can be said that the proposed four-factor structure is consistent with the data set. Then, reliability analyses were conducted. Item-tototal correlations were above .44. The internal consistency of the subscale items were calculated through Cronbach Alpha. The Cronbach Alpha reliability was found to be .81 for the factor of silent in class behaviors ( 3 items), .91 for the factor of oral in class behaviors ( 3 items), .70 for factor of thinking about course content ( 3 items), and .77 for the factor of out of class behaviors ( 4 items). Based on the findings of the study, it can be concluded that the Turkish version of the scale is a valid and reliable instrument to measure university students' engagement. 